\title{
Telómeros y Enfermedad cardíaca
}

\author{
Alexis Lama
}

\section{Señor Editor:}

Diferentes investigaciones han venido señalando el hallazgo que el acortamiento de los telómeros es un marcador de envejecimiento cardiovascular $(\mathrm{CV})^{1}$, que tiene mayor riesgo de mortalidad $\mathrm{CV}$, y mayor riesgo de insuficiencia cardíaca congestiva severa, entre otros. Otras investigaciones más recientes se encuentran explorando el potencial rol de los telómeros, compuestos por patrones repetidos de ácido desoxirribonucleico (ADN) y de la telomerasa en el tratamiento de las enfermedades $\mathrm{CV}$, lo que resulta de gran interés ${ }^{2}$.

Brevemente, la historia de los telómeros se inicia en los años treinta, con el trabajo pionero del genetista norteamericano Hermann Müller, mientras trabajaba en Edimburgo. Müller, el año 1938, usó el termino telómero para referirse a la parte terminal, que a manera de casquete protector ubicado en los extremos de los cromosomas, impedía que estos sufrieran daño al ser irradiados con rayos
$\mathrm{X}$ en experimentos realizados en células de la mosca de la fruta. Müller recibiría el Premio Nobel de Fisiología o Medicina en 1946. Dos años más tarde, Bárbara McClintock, investigadora de la Universidad de Misuri que se dedicaba al estudio de la genética del maíz, demostró que, a pesar del daño al cromosoma, los extremos se podían restaurar gracias a la adquisición de nuevo telómero, concluyendo que estos jugaban un papel crucial en la integridad de los cromosomas. Muchos años después, McClintock recibiría el premio Nobel de Fisiología o Medicina en 1983. Aunque ambas líneas de investigación cesaron por 30 años, se reanudaron con los trabajos de James Watson, acerca de los mecanismos subyacentes a la replicación del ADN. Posteriormente, Alexsei Matveevich Olovnikov, un desconocido científico ruso, halló el eslabón entre el problema de la replicación terminal - enunciado por Watson - y la senescencia celular, a su vez previamente descrita por Leonard Hayflick. Para Olovnikov, el problema de la replicación terminal era la causa del acortamiento 
progresivo de los telómeros que, a su vez, actuaba como un reloj interno para determinar el número de divisiones que la célula podía experimentar a lo largo de su existencia y, por ende, para controlar el proceso de envejecimiento. Al igual que James Watson, Aleksei Oloknikov pensaba que la célula poseía una estrategia para mantener la longitud telomérica durante la replicación normal del ADN. No tardó mucho tiempo en descubrirse que esa estrategia tenía nombre propio. Era la telomerasa, enzima transcriptasa reversa, que repara los telómeros después de perder algunas de sus bases, en cuyo descubrimiento jugó un papel crucial Elizabeth Blackburn, investigadora oriunda de Tasmania, que recibiría el premio Nobel en el año 2009, y cuyo aporte lo haría extensivo al público en un muy importante libro ${ }^{3}$ años más tarde.
Actualmente, las líneas de investigación, aún iniciales, van hacia el uso de terapia génica con telomerasa, modulación inmune para disminuir la inflamación crónica y algunas intervenciones farmacológicas. Entre estas últimas, de interés resulta el uso del llamado TA-65, que contiene una molécula natural extraída de la raíz del astrágalo, hierba muy usada en la medicina china tradicional y que la investigación clínica, aún no definitiva, ha demostrado que activa la telomerasa en humanos ${ }^{4}$. También se sabe que el ejercicio físico ${ }^{5}$, especialmente aeróbico, la dieta mediterránea ${ }^{6}$ y el control del estrés a través de la meditación ${ }^{7}$, son capaces de alargar los telómeros, pudiendo todas ellas ser usadas desde ya en todas las personas, en un intento de prevenir o retrasar la aparición de enfermedades cardíacas.

\section{Referencias}

1. DE MEYER T., NAWROT T., BEKAERT S., DE BUYZEREM., RIETZSCHEL E., M.,.ANDRÉS V. TELOMERE LENGTH AS Cardiovascular Aging Biomarker.J Am Coll Cardiol $2018 ; 72: 805-13$.

2. JIH-KAI YEH, MEI-HSIU LIN, CHAO-YUNG WANG. Telomeres as Therapeutic Targets in Heart Disease. JACC: Basic to Translational Science 2019; 4(7): 855-65.

3. BLACKBURN E. EPPEL E. La Solución de los telómeros, Ediciones Aguilar, 2018.

4. YU Y,ZHOU L, YANG Y, LIU Y. Cycloastragenol: An exciting novel candidate for age-associated diseases. Exp Ther Med. 2018 Sep; 16(3):2175-2182.
5. CROUS-BOU M, FUNG T, PRESCOTT J, et al. Mediterranean diet and telomere length in Nurses' Health Study: population based cohort study. BMJ 2014; 349:g6674.

6. BRANDAO, C., NONINO C., DE CARVALHO F. et al. The effects of short-term combined exercise training on telomere length in obese women: a prospective, interventional study. Sports Med - Open 2020; 6, 5 .

7. KENG S., YIM O., LA P., CHEW S. AND EBSTEIN R. Association among dispositional mindfulness, self-compassion, and leukocyte telomere length in Chinese adults. BMC Psychology 2019; 7: 47. 